\title{
ASPECTOS ÉTICOS E BIOÉTICOS ENCONTRADOS NA ATENÇÃO PRIMÁRIA À SAÚDE
}

\author{
ETHICAL AND BIOETHICS FOUND IN PRIMARY HEALTH CARE
}

\author{
Rose Manuela Marta Santos, Tatiana Almeida Couto, Sérgio Donha Yarid
}

Universidade Estadual do Sudoeste da Bahia - UESB

\begin{abstract}
This research aims to verify in the national and international literature the approach of ethical and bioethical aspects found in primary health care. This is an integrative review research based on the survey of articles in the databases of the Virtual Health Library Portal and Scopus. Complete original articles, available in the English, Portuguese and Spanish languages, were published between 2007 and 2016. Articles of reflection, systematic, integrative and bibliographical review were excluded. To compose the data analysis of this research, 11 articles were selected. The results show that the health professional has difficulty in identifying the ethical problems encountered and has little affinity with the bioethical principles to aid in decision making. However, they understand the importance of reformulating vocational training aimed at training professionals to address these problems. It has become clear that scant researches include the user's view of the problems experienced by them as well as by professionals. It can be concluded that professionals should be able to manage the problems arising from primary care, especially in undergraduate training, as well as research with the user's perspective on the problems.
\end{abstract}

Key words: Ethics; bioethics; Primary Health Care; Health Strategy; Review.

\section{Resumo}

Esta pesquisa tem como objetivo verificar na literatura nacional e internacional a abordagem dos aspectos éticos e bioéticos encontrados na atenção primária à saúde. Trata-se de uma pesquisa de revisão integrativa baseada no levantamento de artigos nas bases de dados do Portal da Biblioteca Virtual em Saúde e Scopus. Foram incluídos artigos originais completos, disponíveis nas línguas inglesa, portuguesa $e$ espanhola publicados no período de 2007 a 2016. Foram excluídos os artigos de reflexão, de revisão sistemática, integrativa e bibliográfica. Para compor a análise de dados desta pesquisa foram selecionados 11 artigos. Os resultados apontam que o profissional de saúde tem dificuldade em identificar os problemas éticos encontrados e tem pouca afinidade com os princípios bioéticos para o auxílio nas tomadas de decisão, no entanto, compreendem a importância da reformulação da formação profissional voltada de forma a capacitar os profissionais para o enfrentamento desses problemas. Tornou-se evidente que são escassas pesquisas que incluem o olhar do usuário diante dos problemas vivenciados tanto por eles quanto pelos profissionais. Pode-se concluir que os profissionais devem estar capacitados para administrarem os problemas advindos da atenção primária, principalmente no que tange a formação na graduação, além de pesquisas com o olhar do usuário sobre os problemas.

Palavras chave: Ética; Bioética; Atenção Primária à Saúde; Estratégia Saúde da Família; Revisão. 
Introdução

Em uma década marcada pelo modelo capitalista de sociedade e da ditadura militar, o contexto histórico de criação de uma sociedade democrática e com respeito aos direitos humanos no Brasil perpassou por movimentos de reivindicações e lutas sociais para alcançar um estado democrático de direito. Tais reivindicações, principalmente contra ao modelo hegemônico e curativista, culminou no movimento da Reforma Sanitária Brasileira que se instaurou como marco na reconstrução da democratização da saúde ${ }^{1}$.

Neste sentido, por influências do movimento reivindicatório por mudanças na oferta dos serviços de saúde, houve a reformulação da Constituição Federal de 1988 incorporando a saúde como direito de todos e dever do estado de garantir os serviços necessários para promover saúde para a população. E, a criação de um Sistema Único de Saúde - SUS como política pública de estado para garantir uma saúde integral, universal e equitativa ${ }^{2}$.

Além da Constituição Federal, o SUS também teve sua formalização na lei $n^{\circ} 8.080 / 90$ que institui a organização, funcionamento e direcionamento das ações de proteção, promoção da saúde, prevenção às doenças e a reabilitação da saúde. E na lei $n^{\circ} 8142 / 90$ que determina as condições de financiamento da saúde e sobre a participação popular ${ }^{3,4}$.

No contexto da prevenção e promoção da saúde e sob os direcionamentos dados na declaração de Alma-Ata no que concerne a Atenção Primária à Saúde, foi lançado o Programa Saúde da Família (PSF) e, por entender esta política como uma estratégia de reordenamento, passou a ser chamada de Estratégia Saúde da Família (ESF). A nova conformação da estrutura da atenção à saúde visa oferecer ações planejadas voltadas para as necessidades que emergem em uma comunidade ${ }^{5}$.

Assim, a ESF visando oferecer uma atenção comunitária, direciona equipes multidisciplinares para as Unidades de Saúde da Família (USF) localizadas em um dado território, a fim de aproximar os profissionais da comunidade. Desta forma, os profissionais que atuam nas comunidades, devem oferecer os serviços de saúde não apenas com foco nas necessidades patológicas, mas também, na dimensão da subjetividade do sujeito ${ }^{6}$.

Assim, em meio à pluralidade das demandas advindas da comunidade os processos de trabalho dos profissionais de saúde da família precisam estar atentos ao estabelecimento de vínculo com a comunidade adscrita e ao respeito aos saberes e crenças do sujeito. Além da sensibilidade dos profissionais em observar os aspectos subjetivos que envolvem a produção do cuidado $^{7}$. Entretanto, diante das diversas demandas, diferenças entre saberes e crenças os profissionais podem se deparar com conflitos gerados na relação profissional-usuário, na qual ambos possuem suas crenças, culturas e valores próprios ${ }^{8}$.

Neste contexto, as situações e/ou problemas que se apresentam aos profissionais em sua atuação profissional estão divididas nos níveis de atenção à saúde, como primários, secundários e terciários. Os problemas éticos são mais evidenciados na literatura no âmbito da atenção secundária e terciária, pois no âmbito hospitalar os profissionais se deparam com casos considerados dilemáticos, como vida e morte e, enquanto na atenção primária os mesmos são considerados menos urgentes e, por conseguinte, menos importantes ${ }^{9}$.

A diferença entre os termos problemas e dilemas éticos foi apresentado pelo autor Diego Gracia $^{10}$, que evidencia que no dilema o profissional deverá escolher entre duas alternativas de resolução e no problema ético há diversas possibilidades de resolução da situação. Neste sentido, considerando a pluralidade das demandas encontradas na APS e do cuidado longitudinal, há diversas formas de resolução das situações, assim, o autor Roque Junges ${ }^{11}$ julga o termo problema ético adequado para utilização diante das situações conflituosas.

Assim, por tratar-se de problemas que ocorrem em uma atenção contínua à saúde, os problemas éticos e bioéticos que emergem na ESF podem passar despercebidos tanto pelos profissionais quanto pelos usuários ${ }^{12}$. Portanto, a não observação destes aspectos e a não identificação dos problemas éticos na atenção primária poderá refletir na assistência prestada à comunidade.

Portanto, este estudo justifica-se pela necessidade de produção científica para a possibilidade de provocar reflexão e mudanças de práticas de cuidados dos profissionais de saúde, especialmente aqueles que desempenham suas funções na Atenção Primária à Saúde. E teve como objeto deste estudo refere-se à ocorrência de problemas éticos na prática profissional na Atenção Primária à Saúde. Assim, esta pesquisa torna-se relevante uma vez que aborda os aspectos éticos e bioéticos no processo de trabalho dos profissionais da ESF no qual é empregado um 
cuidado longitudinal.

Nesse sentido, este estudo teve como questão norteadora: quais os aspectos éticos e bioéticos que envolvem a atenção primária à saúde? Tendo como base essas reflexões, esse estudo tem como objetivo verificar na literatura nacional e internacional a abordagem dos aspectos éticos e bioéticos encontrados na atenção primária à saúde.

\section{Metodologia}

Trata-se de uma pesquisa de revisão integrativa, sendo selecionado este tipo de estudo pela apresentação de rigor metodológico e por permitir o direcionamento de práticas de saúde a partir das evidências científicas ${ }^{13}$. E o levantamento das produções científicas deu-se no período de janeiro a fevereiro de 2017.

O levantamento dos artigos foi realizado na base de dados da Biblioteca Virtual em Saúde (BVS) e Scopus utilizando os descritores: "Ética", "Bioética" e "Atenção Primária à Saúde" nos idiomas português, inglês e espanhol de acordo com os Descritores em Ciências da Saúde (DeCS) e Medical Science Health (MeSH) e, para a combinação dos descritores foi utilizado o operador boleano "and". Foram realizadas as seguintes associações com os operadores booleanos: Ethics AND Bioethics AND Primary Health Care; Ethics AND Bioethics AND Health Strategy; Bioethics AND Primary Health Care e bioethics AND Health Strategy.

Foram definidos também os critérios de inclusão: artigos originais completos; disponíveis nas línguas inglesa, portuguesa e espanhola; que compreendessem as publicações no período de 2007 a 2016 e que contemplassem o objetivo desta pesquisa. Como critério de exclusão: artigos de reflexão, de revisão sistemática, integrativa e bibliográfica.

Após a delimitação de objetivo, dos critérios de inclusão e exclusão e dos critérios de busca, a seleção dos artigos foi realizada por dois pesquisadores separadamente, e posteriormente realizada a conferência dos artigos, analisando as divergências encontradas e ordenando a inclusão ou exclusão dos artigos selecionados.

$\mathrm{Na}$ primeira busca para a seleção dos artigos, foram encontrados 221 artigos. Após a seleção diante dos critérios de inclusão resultaram 91 artigos que foram realizadas leituras dos resumos e títulos a fim de filtrar os artigos que contemplassem o objetivo proposto deste estudo. Assim, restaram 16 artigos, sendo que destes, foram excluídos três artigos em duplicidade e duas revisões de literatura. Portanto, 11 artigos foram selecionados para compor o corpus deste estudo.

\section{Resultados e Discussões}

Para a realização da análise e compreensão dos artigos encontrados $(n=11)$ os dados foram dispostos em quadros. No Quadro 1 os dados estão organizados segundo o autor/ano, a metodologia utilizada, o estado de origem da pesquisa e o periódico no qual foi publicado. 0 Quadro 2 apresenta os dados segundo o título do artigo, os participantes da pesquisa e os principais resultados encontrados.

Quadro 1: Caracterização dos artigos quanto ao autor/ano, a metodologia utilizada, o estado de origem da pesquisa e o periódico no qual foi publicado. Jequié, Bahia, Brasil, 2017.

\begin{tabular}{|c|c|c|c|c|c|}
\hline Artigo & Autor & Ano & Metodologia & Estado & Periódico \\
\hline 01 & $\begin{array}{l}\text { Simas KBF, Simões PP, } \\
\text { Gomes AP, Costa AAZ, } \\
\text { Pereira CG, Siqueira- } \\
\text { Batista } R^{6}\end{array}$ & 2016 & Qualitativa & Rio de Janeiro & $\begin{array}{l}\text { Ciência \& Saúde } \\
\text { Coletiva }\end{array}$ \\
\hline 02 & $\begin{array}{l}\text { Caetano OS, Feltrin JO, } \\
\text { Soratto J, Soratto } \mathrm{MT}^{7}\end{array}$ & 2016 & Qualitativa & Santa Catarina & Saúde e Pesquisa \\
\hline 03 & Motta LCS et al. ${ }^{8}$ & 2015 & $\begin{array}{l}\text { Qualitativa e } \\
\text { quantitativa }\end{array}$ & Rio de Janeiro & Revista Bioética \\
\hline 04 & $\begin{array}{l}\text { Siqueira-Batista } R \text { et } \\
\text { al. }{ }^{9}\end{array}$ & 2015 & Qualitativa & Minas Gerais & Saúde e Sociedade \\
\hline 05 & Schaefer R, Junges JR ${ }^{10}$ & 2014 & Qualitativa & $\begin{array}{l}\text { Rio Grande do } \\
\text { Sul }\end{array}$ & $\begin{array}{l}\text { Escola Enfermagem } \\
\text { USP }\end{array}$ \\
\hline 06 & $\begin{array}{l}\text { Zoboli ELCP, Soares FAC } \\
4\end{array}$ & 2012 & $\begin{array}{ll}\text { Relato } & \text { de } \\
\text { experiência }\end{array}$ & São Paulo & $\begin{array}{l}\text { Escola Enfermagem } \\
\text { USP }\end{array}$ \\
\hline 07 & Junges et al. ${ }^{11}$ & 2012 & Qualitativa & $\begin{array}{l}\text { Rio Grande do } \\
\text { Sul }\end{array}$ & Revista Bioética \\
\hline 08 & $\begin{array}{l}\text { Przenyczka RA, } \\
\text { Kalinowski LC, Lacerda } \\
\text { MR, Wall ML }{ }^{12}\end{array}$ & 2011 & Qualitativa & Paraná & $\begin{array}{l}\text { Ciência Cuidado e } \\
\text { Saúde }\end{array}$ \\
\hline 09 & Brehmer LCF, Verdi $\mathrm{M}^{13}$ & 2010 & Qualitativa & Santa Catarina & $\begin{array}{l}\text { Ciência \& Saúde } \\
\text { Coletiva }\end{array}$ \\
\hline 10 & $\begin{array}{l}\text { Lima AC, Morales DA, } \\
\text { Zoboli ELCP, Sartório } \\
\text { NA }^{14}\end{array}$ & 2009 & $\begin{array}{l}\text { Qualitativa } \mathrm{e} \\
\text { quantitativa }\end{array}$ & São Paulo & $\begin{array}{l}\text { Cogitare } \\
\text { Enfermagem }\end{array}$ \\
\hline 11 & Zoboli ELCP15 & 2007 & Qualitativa & São Paulo & $\begin{array}{l}\text { Acta Paulista de } \\
\text { Enfermagem }\end{array}$ \\
\hline
\end{tabular}


O Quadro 1 demonstra que a maioria das pesquisas foram de abordagem qualitativa $8(72,7 \%), 2(18,2 \%)$ quantitativa e qualitativa, $1(9,1 \%)$ relato de experiência. Quanto aos estados nos quais os artigos foram desenvolvidos, predominaram os estados de São Paulo, Rio de Janeiro, Santa Catarina e Rio Grande do Sul, destacando assim a predominância das regiões Sul e Sudeste nas quais são abordadas esta temática nas pesquisas.
De acordo com o disposto no quadro 2 pode-se verificar que os participantes das pesquisas foram os profissionais que atuam na atenção primária à saúde, sendo composto em sua maioria por médicos, enfermeiros, cirurgiõesdentistas, técnicos em enfermagem, técnicos de higiene oral, agentes comunitários de saúde, agentes de portaria, encarregados de almoxarifado, e em apenas dois estudo foram incluídos os usuários.

Quadro 2: Caracterização dos artigos quanto ao autor/ano, título, participantes da pesquisa e resultados. Jequié, Bahia, Brasil, 2017.

\begin{tabular}{|c|c|c|c|}
\hline $\mathbf{N}^{\circ}$ & TíTULO & PARTICIPANTES & RESULTADOS \\
\hline 01 & $\begin{array}{l}\text { (Bio)ética e Atenção Primária à } \\
\text { Saúde: estudo preliminar nas } \\
\text { Clínicas da Família no município do } \\
\text { Rio de Janeiro, Brasil. }\end{array}$ & $\begin{array}{l}\text { Cento e cinquenta e dois } \\
\text { profissionais da saúde de } \\
\text { diferentes categorias profissionais } \\
\text { de nove Clínicas da Família. }\end{array}$ & $\begin{array}{l}\text { Destacou que o modelo carioca tem } \\
\text { significativas diferenças em relação às } \\
\text { unidades de ESF convencionais, no entanto, } \\
\text { em relação aos problemas éticos possuem } \\
\text { similaridade com os dados de artigos de } \\
\text { outras regiões brasileiras nesta temática, } \\
\text { tais como: problemas envolvendo } \\
\text { equipe/família/usuário, envolvendo os } \\
\text { membros da equipe, envolvendo } \\
\text { equipe/gestão e envolvendo sigilo } \\
\text { profissional. E, propõe ser superadas a par- } \\
\text { tir de uma construção coletiva, da qual } \\
\text { participem todos os envolvidos - usuários, } \\
\text { familias, comunidades, equipes e gestão. }\end{array}$ \\
\hline 02 & $\begin{array}{l}\text { Conduta do enfermeiro frente aos } \\
\text { conflitos éticos e bioéticos em área } \\
\text { vulnerável na ESF }\end{array}$ & $\begin{array}{l}\text { Seis enfermeiros atuantes na ESF } \\
\text { de áreas consideradas } \\
\text { vulneráveis. }\end{array}$ & $\begin{array}{l}\text { A pesquisa demonstrou as dificuldades da } \\
\text { equipe frente à resolutividade dos casos } \\
\text { em área de vulnerabilidade social, o que } \\
\text { requer uma rede de atenção qualificada e } \\
\text { eficaz, equipe multiprofissional capacitada, } \\
\text { comunicação eficaz entre a rede, } \\
\text { preservação do sigilo e privacidade das } \\
\text { informações e humanização do cuidado às } \\
\text { familias. }\end{array}$ \\
\hline 03 & $\begin{array}{l}\text { Em busca do ethos da Estratégia de } \\
\text { Saúde da Família: uma investigação } \\
\text { bioética. }\end{array}$ & $\begin{array}{l}\text { Treze Agentes Comunitários de } \\
\text { Saúde; } \\
\text { dois Técnicos de Higiene Oral; } \\
\text { dois Dentistas; cinco Médicos; } \\
\text { cinco Enfermeiros; quatro } \\
\text { Técnicos de Enfermagem. }\end{array}$ & $\begin{array}{l}\text { O estudo destaca alguns problemas éticos e } \\
\text { bioéticos encontradas na equipe de saúde } \\
\text { sobre: conflito entre as equipes de saúde e } \\
\text { usuários e conflitos entre os membros da } \\
\text { equipe. Foi demonstrada dificuldade em } \\
\text { identificar situações problemáticas, de } \\
\text { caráter bioético. Foi identificado o } \\
\text { desconhecimento por estes profissionais } \\
\text { sobre os princípios da bioética e também, } \\
\text { um consenso de que a ética e bioética } \\
\text { poderia ser melhor abordada na } \\
\text { graduação. }\end{array}$ \\
\hline 04 & $\begin{array}{l}\text { (Bio)ética e estratégia Saúde da } \\
\text { Família: mapeando problemas. }\end{array}$ & $\begin{array}{l}\text { Participaram da investigação } \\
\text { setenta e três profissionais de } \\
\text { quinze equipes da ESF. }\end{array}$ & $\begin{array}{l}\text { O estudo expõem dificuldades quanto à } \\
\text { identificação de situações atinentes aos } \\
\text { problemas (bio)éticos. Foram categorizados } \\
\text { cinco grupos de problemas (bio)éticos } \\
\text { vivenciados pelas equipes: os relacionados } \\
\text { à desigualdade de acesso aos serviços de } \\
\text { saúde; os relacionados à relação ensino- } \\
\text { trabalho-comunidade; os relacionados ao } \\
\text { sigilo e à confidencialidade; os relacionados } \\
\text { aos conflitos entre equipe e usuários; e os } \\
\text { relacionados aos conflitos entre membros } \\
\text { da equipe. }\end{array}$ \\
\hline
\end{tabular}

Continua.. 
...continuação

\begin{tabular}{|c|c|c|c|}
\hline 05 & $\begin{array}{l}\text { A construção da competência ética } \\
\text { na percepção de enfermeiros da } \\
\text { Atenção Primária. }\end{array}$ & $\begin{array}{l}\text { Dez enfermeiros de serviços da } \\
\text { atenção Primária à Saúde. }\end{array}$ & $\begin{array}{l}\text { O estudo evidenciou que todos os } \\
\text { enfermeiros entrevistados já havia } \\
\text { vivenciado situações eticamente conflitivas } \\
\text { em seu trabalho, expressando um domínio } \\
\text { acerca da definição de competência ética. } \\
\text { Consideraram que os valores pessoais, o } \\
\text { ensino e a prática são os pilares que } \\
\text { suportam a construção de um profissional } \\
\text { eticamente competente e que ações com } \\
\text { foco na ética devem ser constantes e } \\
\text { transversais, tanto no âmbito do ensino } \\
\text { quanto da prática. E a importância de } \\
\text { promover iniciativas educacionais e } \\
\text { organizacionais como ferramenta de } \\
\text { enfrentamento do stress moral e contribuir } \\
\text { para melhorar a qualidade do cuidado em } \\
\text { atenção primária à saúde. }\end{array}$ \\
\hline 06 & $\begin{array}{l}\text { Capacitação em bioética para } \\
\text { profissionais } \\
\text { da Saúde da Família do município } \\
\text { de } \\
\text { Santo André, SP. }\end{array}$ & $\begin{array}{l}\text { A amostra foi composta por seis } \\
\text { médicos, seis enfermeiros e um } \\
\text { dentista de uma Unidade Básica } \\
\text { de Saúde. }\end{array}$ & $\begin{array}{l}\text { Os participantes registraram que o curso } \\
\text { deixou-os mais seguros para lidarem com } \\
\text { as situações de conflitos morais. } \\
\text { Compreenderam também, que a dimensão } \\
\text { ética é inalienável da clínica, já que esta } \\
\text { lida, também, com os fatos e os valores } \\
\text { envolvidos na situação, sendo preciso } \\
\text { analisar cada caso sem prejulgamentos. } \\
\text { Reconheceram que os exercícios de } \\
\text { aplicação do procedimento deliberativo } \\
\text { contribuíram para que se apropriassem de } \\
\text { um instrumental para chegarem a decisões } \\
\text { consistentes a argumentadas do ponto de } \\
\text { vista moral. }\end{array}$ \\
\hline 07 & $\begin{array}{l}\text { Hermenêutica dos problemas } \\
\text { éticos percebidos por profissionais } \\
\text { da atenção primária. }\end{array}$ & $\begin{array}{l}\text { Compuseram a amostra das duas } \\
\text { coletas vinte e dois profissionais, } \\
\text { sendo, quatro médicos, cinco } \\
\text { enfermeiras, cinco técnicas de } \\
\text { enfermagem, quatro agentes } \\
\text { comunitários de saúde, um } \\
\text { dentista, um atendente de } \\
\text { portaria, um encarregado do } \\
\text { almoxarifado e um gestor da } \\
\text { unidade. }\end{array}$ & $\begin{array}{l}\text { Os participantes das pesquisas relataram } \\
\text { alguns desafios éticos: na compreensão da } \\
\text { pessoa em sua individualidade, onde é } \\
\text { instaurado o conflito entre a } \\
\text { individualidade do sujeito e os protocolos } \\
\text { definidos pelo sistema; pouco diálogo e } \\
\text { compreensão entre os membros da equipe } \\
\text { gerando conflitos entre os profissionais; a } \\
\text { dificuldade em estabelecer a atuação dos } \\
\text { agentes comunitários de saúde, além da } \\
\text { falta de perfil para trabalhar na ESF. Outro } \\
\text { conflito apontado foi a instabilidade } \\
\text { empregatícia dos profissionais; a } \\
\text { interferência da gestão, fruto de uma } \\
\text { organização e demanda política; e conflitos } \\
\text { gerados entre qualidade da atenção versus } \\
\text { produtividade. }\end{array}$ \\
\hline 08 & $\begin{array}{l}\text { Acolhimento na Atenção Básica: } \\
\text { reflexões éticas sobre a Atenção à } \\
\text { Saúde dos usuários. }\end{array}$ & $\begin{array}{l}\text { A amostra foi composta por vinte } \\
\text { e seis sujeitos, sendo: nove } \\
\text { gestores, dez trabalhadores de } \\
\text { saúde e sete usuários. }\end{array}$ & $\begin{array}{l}\text { Analisado à luz da bioética da proteção, o } \\
\text { acolhimento nas realidades pesquisadas } \\
\text { revelou conflitos éticos que emergem do } \\
\text { dia a dia das ações nos serviços de saúde. } \\
\text { Mostrou distanciamentos técnicos e } \\
\text { conceituais sobre o significado do } \\
\text { acolhimento. Na ótica dos usuários, } \\
\text { sobressaíram diferenças marcantes entre o } \\
\text { Compreenderam também, que a dimensão } \\
\text { ética é inalienável da clínica, já que esta } \\
\text { lida, também, com os fatos e os valores } \\
\text { envolvidos na situação, sendo preciso } \\
\text { analisar cada caso sem prejulgamentos. } \\
\text { Reconheceram que os exercícios de } \\
\text { aplicação do procedimento deliberativo } \\
\text { contribuíram para que se apropriassem de } \\
\text { um instrumental para chegarem a decisões } \\
\text { consistentes e argumentadas do ponto de } \\
\text { vista moral. }\end{array}$ \\
\hline
\end{tabular}


...continuação

\begin{tabular}{|c|c|c|c|}
\hline 09 & $\begin{array}{l}\text { Conflitos éticos da enfermagem } \\
\text { na atenção primária à saúde e } \\
\text { estratégias de enfrentamento. }\end{array}$ & $\begin{array}{l}\text { Treze profissionais de } \\
\text { Enfermagem de uma unidade de } \\
\text { saúde }\end{array}$ & $\begin{array}{l}\text { Os principais conflitos mais citados } \\
\text { foram à violação de sigilo profissional e a } \\
\text { violência contra o idoso e como } \\
\text { estratégias de enfrentamento foram } \\
\text { encontrados: a discussão de casos em } \\
\text { reunião, utilização das redes sociais de } \\
\text { apoio, entre elas o Conselho Tutelar, a } \\
\text { Fundação de Ação Social, o SOS idoso, o } \\
\text { Conselho Municipal dos Direitos da } \\
\text { Pessoa Idosa e o Ministério Público, No } \\
\text { entanto, para alguns profissionais não } \\
\text { estava plenamente claro o papel desses } \\
\text { órgãos. Além de reciclagens constantes } \\
\text { dos profissionais. }\end{array}$ \\
\hline 10 & $\begin{array}{l}\text { Problemas éticos na atenção } \\
\text { básica: a visão de enfermeiros e } \\
\text { médicos. }\end{array}$ & $\begin{array}{l}\text { A amostra foi composta por } \\
\text { trinta e três médicos e trinta } \\
\text { enfermeiros. }\end{array}$ & $\begin{array}{l}\text { O estudo traz como problemas éticos as } \\
\text { dificuldades em estabelecer vínculo, } \\
\text { prejulgamento dos usuários, falta de } \\
\text { respeito, prescrições inadequadas, } \\
\text { acesso dos profissionas de saúde à } \\
\text { intimidade da família, dificuldade em } \\
\text { manter a privacidade do usuário e o } \\
\text { segredo profissional, a atitude dos } \\
\text { profissionais diante das concepções } \\
\text { religiosas dos usuários, falta de } \\
\text { compromisso e envolvimento de alguns } \\
\text { dos profissionais, falta de preparo dos } \\
\text { profissionais para trabalhar na ESF, } \\
\text { quebra do sigilo médico por outros } \\
\text { membros, dificuldade para preservar } \\
\text { privacidade, falta de apoio com ações } \\
\text { intersetoriais, falta de transparência da } \\
\text { direção da Unidade, excesso de familias } \\
\text { adscritas, dificuldades para realizar } \\
\text { exames complementares, menores de } \\
\text { idade que pedem à equipe } \\
\text { procedimentos e exames sem } \\
\text { autorização ou conhecimento de seus } \\
\text { pais, falta de serviço de retaguarda. }\end{array}$ \\
\hline 11 & $\begin{array}{l}\text { Enfermeiros e usuários do } \\
\text { Programa Saúde da Família: } \\
\text { contribuições da bioética para } \\
\text { reorientar esta relação } \\
\text { profissional }\end{array}$ & $\begin{array}{l}\text { Dezessete enfermeiros de } \\
\text { equipes de Saúde da Família do } \\
\text { Município de São Paulo. }\end{array}$ & $\begin{array}{l}\text { A dimensão ética na atenção básica lida } \\
\text { com situações corriqueiras da prática } \\
\text { cotidiana É urgente o redirecionamento } \\
\text { da sensibilidade dos enfermeiros para a } \\
\text { percepção da sutileza dos problemas } \\
\text { éticos nas relações com os usuários na } \\
\text { atenção básica. A ponderação e } \\
\text { especificação dos princípios da } \\
\text { autonomia, não maleficência, justiça e } \\
\text { beneficência, enriquecidas por outros } \\
\text { enfoques da bioética, podem contribuir } \\
\text { para a construção da cidadania e } \\
\text { promoção da saúde. }\end{array}$ \\
\hline
\end{tabular}

Com relação à temática dos aspectos éticos e bioéticos na atenção primária à saúde com pesquisa de campo, pode-se notar que os estudos sobre este assunto ainda são incipientes no âmbito da produção científica no Brasil. No que tange aos estados ao quais os artigos pertencem, é válido ressaltar que as primeiras investigações referentes aos problemas éticos e bioéticos na atenção primária à saúde começaram a ser realizadas a quase uma década na Universidade de São Paulo, o que pode justificar a concentração dos artigos encontrado nas regiões sudeste e sul.

As pesquisas que foram analisadas trouxeram importantes resultados no que diz respeito aos aspectos éticos e as concepções bioéticas encontrados no processo de trabalho dos profissionais que atuam na atenção primária à saúde.

Neste contexto, estudo realizado com o intuito de identificar e caracterizar questões bioéticas na atenção primária à saúde 
demonstrou em seus resultados a ocorrência de conflito entre as equipes de saúde e os usuários, além de conflitos entre os membros da equipe da ESF. Também foi demonstrada a dificuldade encontrada pelos profissionais em identificar as situações de conflito ético, bem como a dificuldade de relacioná-los com os princípios bioéticos ${ }^{16,17}$.

Diante das situações práticas que costumam acontecer na assistência ao usuário, estas não podem ser analisadas apenas diante do embasamento da bioética principialista que considera os princípios da autonomia, beneficência, justiça e não-maleficência. Pois, por exemplo, diante da tomada de decisão sobre as formas de tratamento a serem seguidas deve ser considerado o envolvimento entre os membros da equipe, o usuário e a família para se evitar a vulnerabilidade às ações instintivas para garantir a integridade pessoal e profissional ${ }^{23}$.

Pesquisas que objetivaram identificar e verificar a frequência dos problemas éticos vividos por enfermeiros e médicos da atenção primária à saúde destacaram as situações que ocorrem no processo de trabalho, como a falta de respeito, prescrições erradas, questões relacionadas à privacidade, quebra de sigilo por membros da equipe, falta de ações intersetoriais, excesso de famílias adscritas. E quanto à frequência com que ocorrem esses problemas, os mais relatados foram a falta de respeito, questionamentos das prescrições médicas, quebra do sigilo, dificuldade em manter a privacidade, falta de apoio para resolução dos problemas com a equipe ${ }^{14,21}$.

Assim, na sociedade plural existente os profissionais de saúde constantemente são exigidos às tomadas de decisões diante de casos envolvendo complexos problemas éticos em que é necessário o respeito às opções morais dos usuários. Dessa forma, a relevância de que as propostas diagnósticas, de tratamento e o cuidado a serem prestados pela equipe de saúde sejam adequados a essa realidade ${ }^{24}$.

Neste sentido, em estudo são ressaltados problemas com o diálogo entre a equipe, dificuldade em estabelecer os limites da atuação sigilosa dos agentes comunitários, falta de perfil de alguns profissionais para trabalhar na ESF e, o estudo ainda identificou outros aspectos éticos relatados pelos profissionais como a instabilidade empregatícia, interferência da gestão com demandas políticas e o conflito entre atenção à saúde com qualidade ou a produtividade ${ }^{25}$.

Um aspecto importante a ser destacado nos estudos foi identificação de que os profissionais têm dificuldades em compreender as situações como problemas éticos, bem como o desconhecimento dos princípios bioéticos para dar base à tomada de decisões frente aos problemas $^{16,17,20}$.

Por sua vez, as relações éticas entre profissionais da saúde, os usuários e a família são uma relevante base para a eficácia da adesão aos tratamentos de saúde, assim como uma forma de reduzir as infrações éticas ${ }^{26}$.

Neste contexto, diante das problemáticas existentes na atenção em saúde no âmbito da atenção primária e a dificuldade dos profissionais em reconhecê-las, estudo demonstrou que uma alternativa para superar estes obstáculos na condução do processo de trabalho é a discussão em coletivo envolvendo os usuários, as famílias e a comunidade, além da equipe e dos gestores ${ }^{14}$.

Outras questões que envolvem problemas éticos na ESF foram levantadas por autores, destacam que os profissionais têm dificuldades em compreender o significado do acolhimento, tornando-o como uma estratégia de recepção, triagem e encaminhamento. Ou seja, toda a demanda e estratégia seguindo o fluxo de um modelo biomédico, pelo distanciamento técnico e das concepções do significado do acolhimento entre os profissionais ${ }^{19,20}$.

Portanto, a necessidade de que na formação dos profissionais prevaleça a percepção e a valorização do outro, seja este um membro da equipe e/ou o usuário. Pois, na atuação na atenção básica além dos aspectos técnicos há a exigência de valores, o conhecimento, o embasamento ético. E para a efetivação são necessárias novas configurações e técnicas de trabalho multiprofissionais ${ }^{27}$.

Ainda, os mesmos autores trazem em suas pesquisas as situações consideradas como problemas éticos, segundo a visão dos usuários, onde foram constatadas as frustrações dos mesmos sobre o real desejo de se sentirem acolhidos e com respeito, tendo suas necessidades atendidas, o que gera sentimentos de exclusão e negação à saúde dos usuários ${ }^{19,20}$. Válido ressaltar que estas foram os únicos estudos encontrados nesta pesquisa que trouxe a realidade dos problemas éticos segundo os usuários.

Outro aspecto encontrado neste estudo foi a dificuldade da equipe direcionar as problemáticas identificadas à rede de atenção, principalmente em casos de vulnerabilidade social. Destacou que a resolutividade exige uma equipe multiprofissional capacitada, comunicação eficaz, escuta qualificada, e privacidade e sigilo na condução do fato ${ }^{15}$.

$\mathrm{Na}$ tomada de decisão percebe-se que é 
necessário o reconhecimento e ampliação do olhar sobre a possibilidade de que parte do raciocínio será subjetivo, mesmo que a racionalidade seja explícita. Portanto, a atenção primária à saúde representa um campo com peculiaridade de problemas éticos passíveis de serem vividos e enfrentados pelos profissionais em atuação ${ }^{28}$.

Diante disso, é importante destacar que a dimensão ética na atenção primária à saúde perpassa por situações diárias no cotidiano das equipes de saúde e é imprescindível a sensibilização dos enfermeiros para a percepção dos problemas encontrados. Para que os profissionais de saúde estejam atentos aos problemas quase imperceptíveis, a autora afirma que o foco deve ser individualizar cada problema, para direcionar as ações de tomada de decisão ${ }^{22,29}$.

Foi identificado também nesta pesquisa o reconhecimento de que a ética e a bioética devem ser implementadas transversalmente nas disciplinas da formação em saúde. Bem como, a importância do oferecimento de atividades educacionais voltadas para a discussão e enfrentamento dos problemas éticos encontrados na atuação profissional ${ }^{16,18}$.

Percebe-se que o ensino da ética nos cursos de saúde apenas pelas discussões e aprendizados da deontologia não são suficientes para atender às demandas da formação humanística dos profissionais da saúde. Sendo importante a substituição da aprendizagem por transmissão de informações e a inserção de discussões baseadas na prática entre o docente, o discente e de acordo à realidade social no qual estão inseridos. Portanto, o ensino da ética e da bioética de forma transversal nos cursos de graduação oferece uma possibilidade de visão multidisciplinar e mais abrangente da moralidade humana ${ }^{24}$.

É fundamental que o docente durante o processo formativo assuma a responsabilidade quanto à dimensão ética e que exista o aprendizado e a apreensão pelos discentes, por ser esta uma possibilidade integral do ser humano ${ }^{30}$.

Em relato de experiência sobre uma capacitação em bioética, os profissionais relataram que ficaram mais seguros para lidarem com as situações de conflito após participarem de tal atividade ${ }^{8}$.

Destarte, diante de um contexto histórico de formação profissional alicerçado no modelo biomédico e tecnicista é relevante a organização das práticas de capacitação dos profissionais que se deparam constantemente com problemas de cunho ético. No intuito de sensibilizar e direcionar os profissionais para a observação dos princípios da bioética para que os problemas éticos sejam melhores conduzidos pela equipe de saúde, faz-se necessário a reorientação dos profissionais para que atuem eticamente diante da pluralidade que envolve a assistência na atenção primária à saúde ${ }^{21}$.

\section{Conclusões}

Foi possível perceber que os principais problemas éticos encontrados na ESF estão relacionados com a interação entre profissional/usuário, as relações entre os membros da equipe e as relações dos profissionais com a rede assistencial de saúde. E, quando os profissionais não conseguem perceber tais problemas, a produção do cuidado fica comprometida, no que tange ao cuidado prestado e aos direcionamentos na tomada de decisão.

A dificuldade dos profissionais em compreender que os problemas éticos também podem emergir a partir do primeiro contato do usuário na unidade, como no acolhimento faz com que tal prática seja executada apenas como um processo de triagem. Não observando assim, questões subjetivas que os usuários apresentam como necessidade e, por conseguinte, os problemas advindos desta prática podem acarretar em tomadas de decisão precipitadas e sem ao menos observar os princípios bioéticos que ajudam no direcionamento e na resolução dos problemas éticos encontrados no processo de trabalho.

Foi destacado também a importância da capacitação dos profissionais e o reforço da formação profissional com discussões interdisciplinares dos problemas éticos que os profissionais se deparam em sua atuação bem como, com os direcionamentos embasados nos princípios bioéticos.

O que torna evidente é que apesar dos estudos sobre a temática ética e bioética na atenção primária à saúde se destacarem a uma década, os dados encontrados se remetem aos problemas éticos sob a visão dos profissionais. Escassos os estudos nos quais são discutidos os problemas éticos advindos do processo de trabalho da equipe de saúde da família sob o olhar do usuário, considerando que o mesmo também faz parte do projeto terapêutico ao qual estão submetidos pelos profissionais. Nesta pesquisa, apenas dois estudos incluíram os usuário nas discussões. 
Assim, este estudo apresenta como contribuições a possibilidade da sensibilização dos discentes da área de saúde no momento de sua formação profissional, por meio da implementação dos conteúdos de ética e bioética de forma transversal, de modo a capacitar os discentes para a condução e tomada de decisão diante dos problemas éticos advindos do processo de trabalho na atenção primária à saúde. Além disso, é necessária a reflexão e mudanças de práticas de cuidados dos profissionais de saúde, especialmente aqueles que desempenham suas funções na Atenção Primária à Saúde.

Portanto, sugerem-se como investigações futuras a percepção dos usuários sobre os aspectos éticos e bioéticos no cuidado produzido por profissionais em unidades de saúde.

\section{Referências}

1. Paim JS. Reforma Sanitária Brasileira: contribuição para a compreensão e crítica. Salvador: EDUFBA; Rio de Janeiro: FIOCRUZ; 2008.

2. Brasil. Constituição Federal Brasileira de 5 de outubro de 1988. Brasília, 1988.

3. Brasil. Lei $n^{\circ} 8.080$ de setembro de 1990. Dispõe sobre as condições para a promoção, proteção e recuperação da saúde, a organização e o funcionamento dos serviços correspondentes e dá outras providências. Brasília; 1990.

4. Brasil. Lei $n^{\circ} 8142$ de 28 de dezembro de 1990. Dispõe sobre a participação da comunidade na gestão do Sistema Único de Saúde (SUS) e sobre as transferências intergovernamentais de recursos financeiros na área da saúde e dá outras providências. Brasília; 1990.

5. Hino P, Ciosak SI, Fonseca RMGS, Egry EY. Necessidades em saúde e atenção básica: validação de Instrumentos de Captação. Rev Esc Enferm. 2009; 43(Supl. 2): 1156-67.

6. Ministério da Saúde (BR). Política Nacional de Atenção Básica. Secretaria de Atenção à Saúde. Departamento de Atenção Básica. Brasília: Ministério da Saúde; 2012.

7. Franco TB, Merhy EE. Mapas analíticos: una mirada sobre la organización y sus procesos de trabajo. Salud colectiva. 2009; 5(2):181-94,

8. Assis MMA, et al., organizadores. Dimensões teóricas e metodológicas da produção do cuidado em saúde. Salvador: EDUFBA; 2010.

9. Zoboli ELCP, Soares FAC. A training course on bioethics for Family Health Strategy professionals in Santo André, SP. Rev Esc Enferm USP. 2012; 46(5): 1248-53.

10. Gracia DJC. La deliberación moral en bioética. Interdisciplinariedad, pluralidad, especialización. Ideas y Valores. 2011; LX(147):25-50.

11. Junges JR. Bioética da atenção primária à saúde. Revista da AMRIGS. 2011; 55(1):88-90.

12. Vidal SV, Motta LC de S, Gomes AP, Siqueira-Batista R. Problemas bioéticos na Estratégia Saúde da Família: reflexões necessárias. Rev. Bioét. (Impr.). 2014; 22(2): 34757.

13. Whittemore R, Knafl K. The integrative review: updated methodology. J Adv Nurs. 2005; 52(5):546-53.

14. Simas KBF, Simões PP, Gomes AP, Costa $A A Z$, Pereira CG, Siqueira-Batista R. (Bio)ética e Atenção Primária à Saúde: estudo preliminar nas Clínicas da Família no município do Rio de Janeiro, Brasil. Ciência \& Saúde Coletiva. 2016; 21(5):1481-90.

15. Caetano OS, Feltrin JO, Soratto J, Soratto MT. Conduta do enfermeiro frente aos conflitos éticos e bioéticos em área vulnerável na ESF. Revista Saúde e Pesquisa. 2016; 9(2):349-60.

16. Motta LCS, et al. En busca del ethos de la Estrategia Salud de la Familia: una investigación bioética. Rev. Bioét. (Impr.). 2015; 23(2):366-79.

17. Siqueira-Batista $R$, et al. (Bio)ethics and Family Health Strategy: mapping problems. Saúde Soc. 2015; 24(1):113-28.

18. Schaefer R, Junges JR. A construção da competência ética na percepção de enfermeiros da Atenção Primária. Rev Esc Enferm USP. 2014; 48(2):329-34.

19. Przenyczka RA, Kalinowski LC, Lacerda MR, Wall ML. Conflitos éticos da enfermagem na atenção primária à saúde e estratégias de enfrentamento. Cienc Cuid Saude. 2011; 10(2):330-37.

20. Brehmer LCF, Verdi M. Acolhimento na Atenção Básica: reflexões éticas sobre a Atenção à Saúde dos usuários. Ciência \& Saúde Coletiva. 2010; 15(Supl.3):3569-78.

21. Lima AC, Morales DA, Zoboli ELCP, Sartório NA. Problemas éticos na atenção básica: a visão de enfermeiros e médicos. Cogitare Enferm. 2009; 14(2):294-303.

22. Zoboli ELCP. Enfermeiros e usuários do Programa Saúde da Família: contribuições da bioética para reorientar esta relação profissional. Acta Paul Enferm. 2007; 20(3):316-20.

23. D'Arco C, Ferrari CMM, Carvalho LVB, Priel MR, Pereira LL. Obstinação terapêutica sob o referencial bioético da vulnerabilidade na prática da enfermagem. O Mundo da Saúde. 
2016; 40(3):382-89.

24. Siqueira JE. Educação bioética para profissionais da saúde. Revista Bioethikos. 2012; 6(1):66-77.

25. Junges JR, et al. Hermenêutica dos problemas éticos percebidos por profissionais da atenção primária. Rev. Bioét (Impr.). 2012; 20(1):97-105.

26. Pimentel D. Relações e conflitos éticos na prática de médicos e enfermeiros. Brasília: CFM; 2017.

27. Haddad JGV, Zoboli ELCP. O Sistema Único de Saúde e o giro ético necessário na formação do enfermeiro. 0 Mundo da Saúde. 2010; 34(1):86-91.

28. Ferreira DC, Silva Junior AG, Batista RS. A Bioética na Tomada de Decisão na Atenção Primária à Saúde. Revista Brasileira de Educação Médica. 2015; 39(3):479-85.

29. Zoboli ELCP. Tomada de decisão em bioética clínica: casuística e deliberação moral. Rev Bioét (Impr.). 2013; 21(3):389-96.

30. Finkler M, Caetano JC, Ramos FRS. Ética e valores na formação profissional em saúde: um estudo de caso. Ciência \& Saúde Coletiva. 2013; 18(10):3033-42.

\section{Endereço para Correspondência}

Universidade Estadual do Sudoeste da Bahia UESB

Rua José Moreira Sobrinho, sn - Jequiezinho, Jequié - BA,

CEP .: 45208-091

e-mail: rosemmarta@gmail.com

Recebido em 28/08/2017

Aprovado em 02/05/2018

Publicado em 11/05/2018 